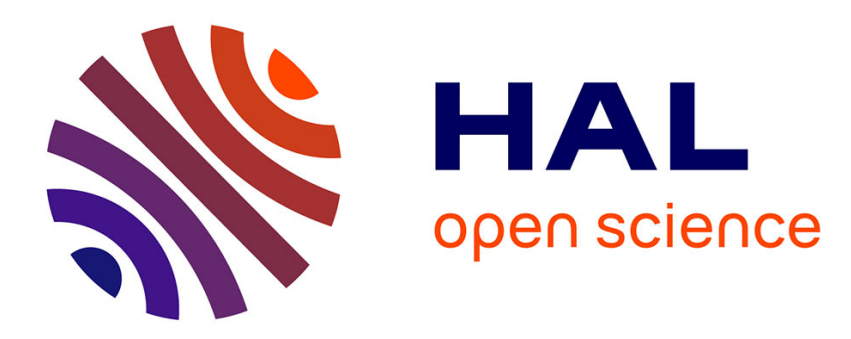

\title{
Fatigue of High Purity Copper Wire
}

\author{
N. Tanabe, A. Kurosaka, K. Suzuki, O. Kohno
}

\section{To cite this version:}

N. Tanabe, A. Kurosaka, K. Suzuki, O. Kohno. Fatigue of High Purity Copper Wire. Journal de Physique IV Proceedings, 1995, 05 (C7), pp.C7-389-C7-396. 10.1051/jp4:1995747 • jpa-00254042

\section{HAL Id: jpa-00254042 https://hal.science/jpa-00254042}

Submitted on 1 Jan 1995

HAL is a multi-disciplinary open access archive for the deposit and dissemination of scientific research documents, whether they are published or not. The documents may come from teaching and research institutions in France or abroad, or from public or private research centers.
L'archive ouverte pluridisciplinaire HAL, est destinée au dépôt et à la diffusion de documents scientifiques de niveau recherche, publiés ou non, émanant des établissements d'enseignement et de recherche français ou étrangers, des laboratoires publics ou privés. 


\title{
Fatigue of High Purity Copper Wire
}

\author{
N. Tanabe, A. Kurosaka*, K. Suzuki and O. Kohno
}

Materials Research Laboratory, Fujikura Ltd. 1-5-1, Kiba, Koto-ku, Tokyo 135, Japan

*Advanced Technology R\&D Center, Fujikura Ltd. 1-5-1, Kiba, Koto-ku, Tokyo 135, Japan

\begin{abstract}
The fatigue properties of $7 \mathrm{~N}, \mathrm{OFC}$ and Tough-Pitch copper wires were evaluated by a rotational bending method. $7 \mathrm{~N}$ copper wires, having RRR300K/4.2K of 7600, were produced by electro-refining, vacuum melting, zonerefining followed by suitable drawing processes, using $4 \mathrm{~N}$ class commercial OFC plates as the starting material. The fatigue failure cycles of $7 \mathrm{~N}$ copper increased with an increased pause period imposed during the fatigue test after $5 \times 10^{6}$ cycles. Remarkable recrystallizations initiated from the wire surface occurred in $7 \mathrm{~N}$ copper after the pause period in the fatigue test. Strains accumulated during fatigue are considered to act as the driving force. It is expected that $7 \mathrm{~N}$ copper can recover from fatigue by itself during practical service use and show excellent fatigue resistance.
\end{abstract}

\section{INTRODUCTION}

The annealing properties of copper change greatly when it is purified up to 6 or $7 \mathrm{~N}$ level $[1,2]$. The annealing temperature of $7 \mathrm{~N}$ class high purity copper is less than $100^{\circ} \mathrm{C}$ and not only recovery of point defects or dislocations but also recrystallizations occur even at room temperature after cold work [3]. The activation energy for recrystallization [2-7] in $7 \mathrm{~N}$ class zone-refined copper was estimated as $0.82 \mathrm{eV}$ [2] from relations between tensile strength and measuring temperature. This is very low compared with the $1.82 \mathrm{eV}$ [7] of usual Tough Pitch copper. This characteristic of high purity copper makes it appreciable as material for electric wires and flexible printed circuits (FPC), because it can be "self-annealed" and its electrical and mechanical properties can modify themselves after fabrication.

We further expected that high purity copper would have excellent fatigue resistance. Defects and strains accumulated by fatigue could rectify themselves by recrystallization. In this study, the fatigue properties of $7 \mathrm{~N}$ class zone-refined copper wire were investigated. 


\section{EXPERIMENTAL PROCEDURES}

\subsection{Purification and wire drawing}

The details of fabrication of the high purity copper wires have been described elsewhere [2]. 4N class commercially available oxygen free copper (OFC) plates were used as the starting material. A $\Phi 16.5 \mathrm{~mm}$ rod was produced by electro-refining in a sulphuric acid bath, vacuum melting under $5 \times 10^{-2} \mathrm{~Pa}$ and zonerefining with a zone transfer rate of $50 \mathrm{~mm} / \mathrm{hr}$. The rod was swaged to $5.0 \mathrm{~mm}$ and drawn to $2.0 \mathrm{~mm}$ in diameter. Etch-cleanings were conducted in the procedure in order to remove contaminations embedded in the wire surface during the cold work. The sample wire showed $R_{R R} R_{300 K / 4.2 K}$ of 7600 (value after size effect correction). According to GDMS analyses, the nominal purity of the refined copper wire was in $7 \mathrm{~N}$ class (hereafter we refer to purified copper as $7 \mathrm{~N}$ copper).

\subsection{Fatigue tests}

Table 1 Tensile strength of sample wires.

\begin{tabular}{c|c|c|c}
\hline \multirow{2}{*}{$\begin{array}{c}\text { Sample wires } \\
\Phi_{2.0 \mathrm{~mm}}\end{array}$} & $\begin{array}{c}\text { As cold worked } \\
(\%)\end{array}$ & \begin{tabular}{c} 
As annealed* \\
\cline { 2 - 4 }
\end{tabular} & $\begin{array}{c}\text { Reduction } \\
(\mathrm{MPa})\end{array}$ \\
\hline Tough Pitch Cu & 93.4 & 456 & $\begin{array}{c}\text { Tensile strength } \\
(\mathrm{MPa})\end{array}$ \\
OFC & 93.4 & 452 & 229 \\
$7 \mathrm{~N}-\mathrm{Cu}$ & 98.5 & 422 & 228 \\
& & & 189 \\
\hline
\end{tabular}

$\Phi 2.0 \mathrm{~mm}$ cold worked wires of the $7 \mathrm{~N}$ copper, OFC and Tough Pitch copper were presented for fatigue testing. The OFC and Tough-Pitch copper wires were drawn from $\Phi 8.0 \mathrm{~mm}$ wire rods. The tensile strength of sample wires is shown in Table 1. Fatigue tests were carried out at $25^{\circ} \mathrm{C}$ in an air-conditioned room by a rotational bending method shown in Fig.1. In the test, a constant bending stress is applied repeatedly to a testing length of a wire until it breaks by failure. Relations between load and applied stress are given by the following equation,

$$
\begin{array}{cll}
\sigma_{\mathrm{w}}=16 \mathrm{LW} / \pi \mathrm{d}^{3} & & \\
\text { where } & \sigma_{\mathrm{w}} & \text { applied stress } \\
& \mathrm{W} & \text { load } \\
& \mathrm{L} & \text { span of bending beam (testing length) } \\
& \text { d } & \text { diameter of a sample wire. }
\end{array}
$$

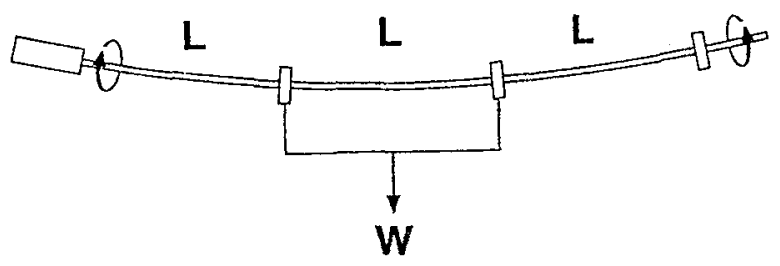

Fig.1 Schematic representation of rotational bending fatigue test. 
The length of a sample wire was $350 \mathrm{~mm}$ and $\mathrm{L}$ of the wire was $100 \mathrm{~mm}$. The rotation rate was fixed at $4000 \mathrm{rpm}$ (corresponding to $67 \mathrm{~Hz}$ ). Relations between applied stress $(\mathrm{MPa})$ and induced strain $(\mu \mathrm{ST})$ at the surfaces of sample wires were directly measured by strain-gauges as follows,

$$
\begin{array}{ll}
\varepsilon_{\mathrm{w}}=8.88 \cdot \sigma_{\mathrm{w}} & (7 \mathrm{~N} \text { copper }) \\
\varepsilon_{\mathrm{w}}=7.34 \cdot \sigma_{\mathrm{w}} & (\mathrm{OFC}) \\
\varepsilon_{\mathrm{w}}=6.95 \cdot \sigma_{\mathrm{w}} & \text { (Tough Pitch copper })
\end{array}
$$

\section{RESULTS}

\subsection{Recrystallizations at room temperature}

Fig. 2 shows microstructures of longitudinal sections of $\Phi 2.0$ and $0.50 \mathrm{~mm} 7 \mathrm{~N}$ copper wires aged for 1 day and 4 months at room temperature after drawing. Remarkable recrystallizations are observed in samples after 4 months. Fig. 3 shows changes of tensile strength in the wires as a function of time after drawing. It decreased to almost full-annealing level after 2 months due to recrystallizations. The rate of recrystallization was higher in the $\Phi 0.50 \mathrm{~mm}$ wire, because of the greater strains accumulated during cold work.

$\phi 0.5 \mathrm{~mm}$ (Red. 99.9\%)

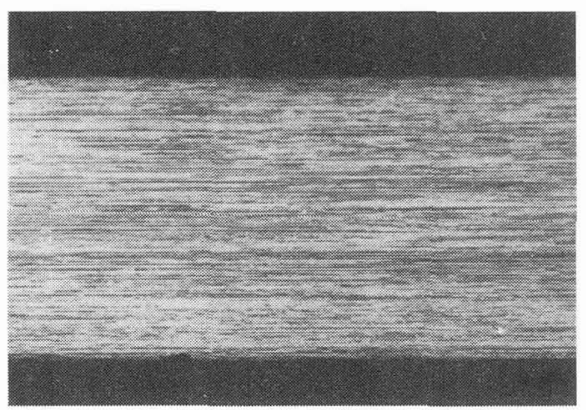

$\phi 2.0 \mathrm{~mm}$ (Red. 98.5\%)

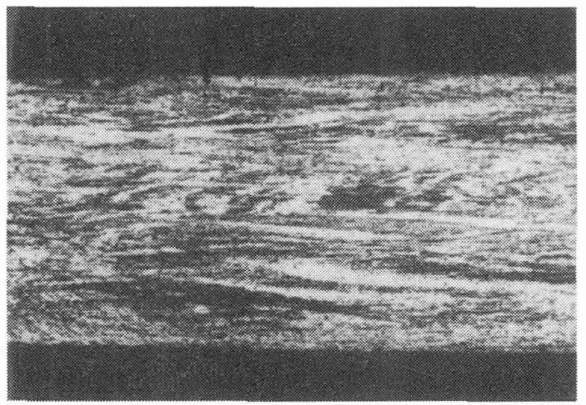

after 1 day
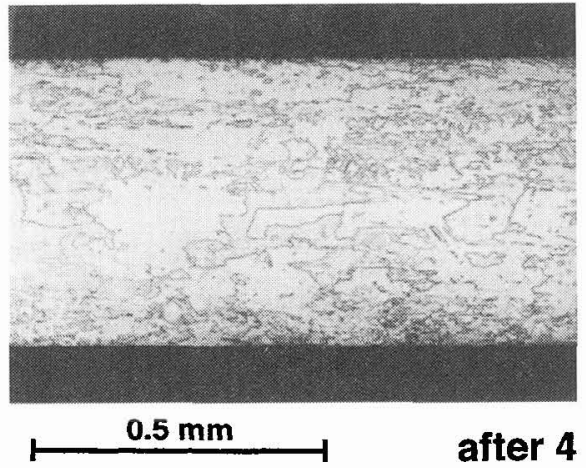

after $\mathbf{4}$ months

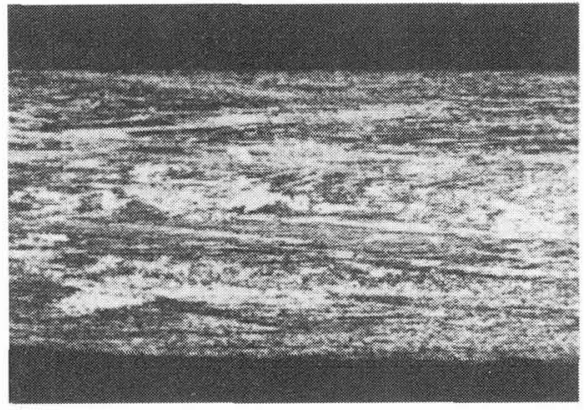

$1 \mathrm{~mm}$

Fig.2 Microstructures of longitudinal sections of $\Phi 2.0$ and $0.50 \mathrm{~mm} 7 \mathrm{~N}$ copper wires aged for 1 day and 4 months at room temperature after drawing. 


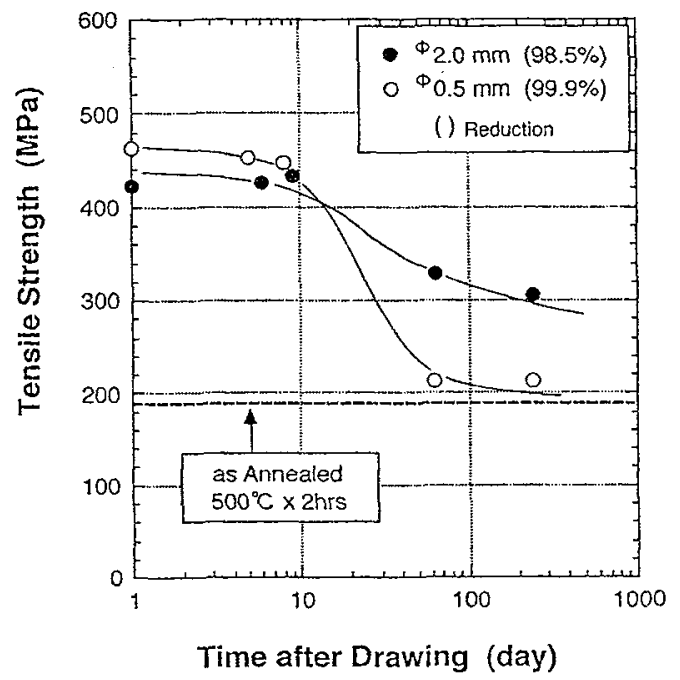

Fig.3 Tensile strength of $\Phi 2.0$ and $0.50 \mathrm{~mm} 7 \mathrm{~N}$ copper wires as a function of aging time at R.T. after drawing.

\subsection{Fatigue properties}

Fig. 4 shows $\mathrm{S}-\mathrm{N}$ curves (relations between applied stress and fatigue failure cycles) of $\Phi 2.0 \mathrm{~mm}$ cold worked $7 \mathrm{~N}$, OFC and Tough-Pitch copper wires measured within 2 months after drawing. The fatigue limit stress of $7 \mathrm{~N}$ copper was obtained as 53.9 $\mathrm{MPa}$, which was the smallest value of the samples, because $7 \mathrm{~N}$ copper is rather soft and bends easily under a bending stress compared with other samples. Fig. 5 shows rearranged relations of Fig. 4 as relations between induced strain and fatigue failure cycles. In the relations, the fatigue properties are almost the same as for the other samples.

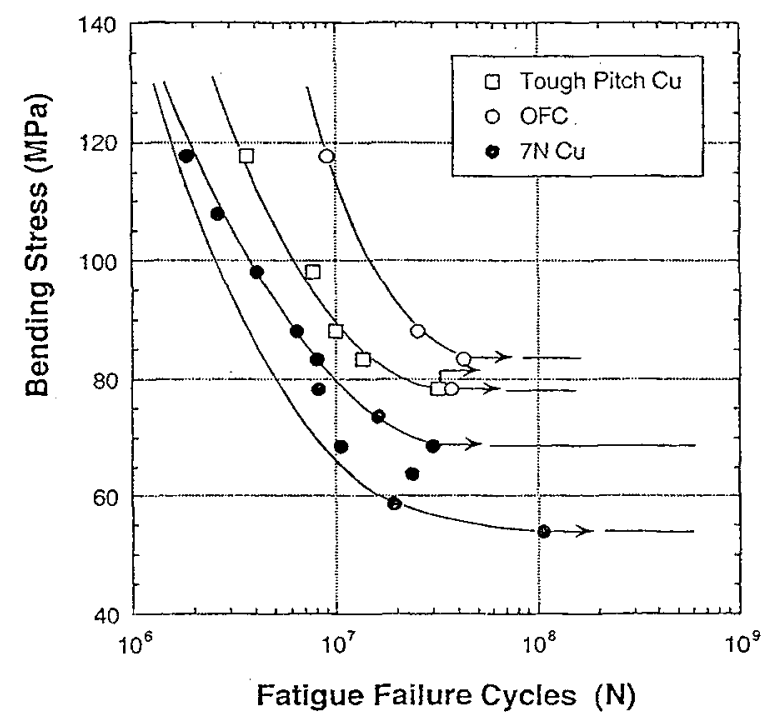

Fig.4 S-N curves of $\$ 2.0 \mathrm{~mm}$ cold worked $7 \mathrm{~N}$, OFC and 'Tough Pith copper wires.

In the fatigue property mentioned above, we did not find any strong points for $7 \mathrm{~N}$ copper. But we found that remarkable recrystallizations occurred in $7 \mathrm{~N}$ copper wires after fatigue tests. They initiated from the wire surface where the largest strains are induced by bending. The wire rotation rate of $4000 \mathrm{rpm}$ was chosen as the lowest rate of our testing machine. But in these conditions, the operation period for $10^{7}$ cycles, which is regarded as infinite for fatigue cycles in general, is only 1.7 days. It is higher than recrystallization rate at room temperature. 


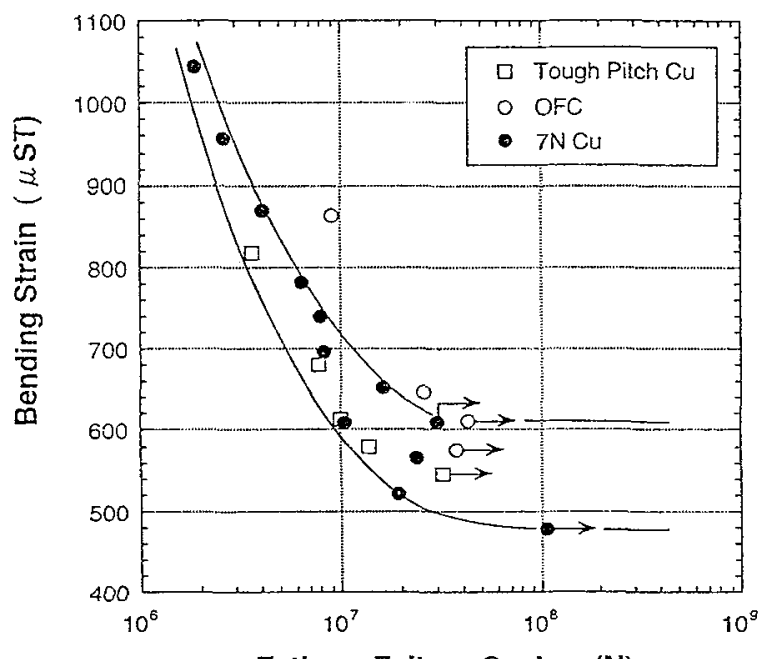

Fatigue Failure Cycles ( $N$ )

Fig.5 Re-arranged relations of Fig.4 as relations between induced strain and fatigue failure cycles.

\subsection{Effects of recrystallization on fatigue}

In order to investigate the effects of recrystallization on fatigue properties, we set a pause period in the fatigue test as shown in Fig.6. When the fatigue cycle reached $5 \times 10^{6}$, the test machine operation was stopped for 1,10 and 30 days as a pause period. During this period the samples were kept at $25^{\circ} \mathrm{C}$ in the air conditioned room. After the period, the test machine operation was started again and continued until fatigue failure occurred. Tests were carried out on $7 \mathrm{~N}$ and Tough Pitch copper wires at stresses calculated to give the same strains of $700 \mu \mathrm{ST}$ at each wire surface.

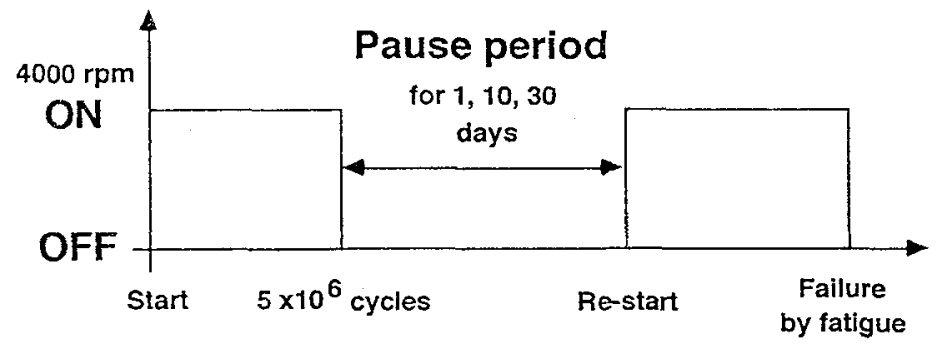

\section{Increasing Time / Cycles}

Fig.6 A pause period settled in the fatigue test.

Fig.7 shows relations between total fatigue failure cycles and the pause period. In $7 \mathrm{~N}$ copper, the fatigue failure cycle increased up to twice with an increasing pause period, although no increase was recognized in Tough Pitch copper. Fig. 8 shows microstructures of longitudinal sections of $7 \mathrm{~N}$ and Tough Pitch copper wires which have spent 10 days as a pause period after the initial fatigue cycles. Remarkable recrystallizations were observed in the surface area of $7 \mathrm{~N}$ copper. On the other hand, fibre structures formed by drawing were still observed in the core area and in all areas of Tough Pitch copper. Fig. 9 shows 
hardness distributions of sample wires. During the pause period, hardness of the surface area in $7 \mathrm{~N}$ copper decreased to full-annealing level, while no change was observed in Tough-Pitch copper. The results of the hardness measurements correspond to the microstructures shown in Fig.8.

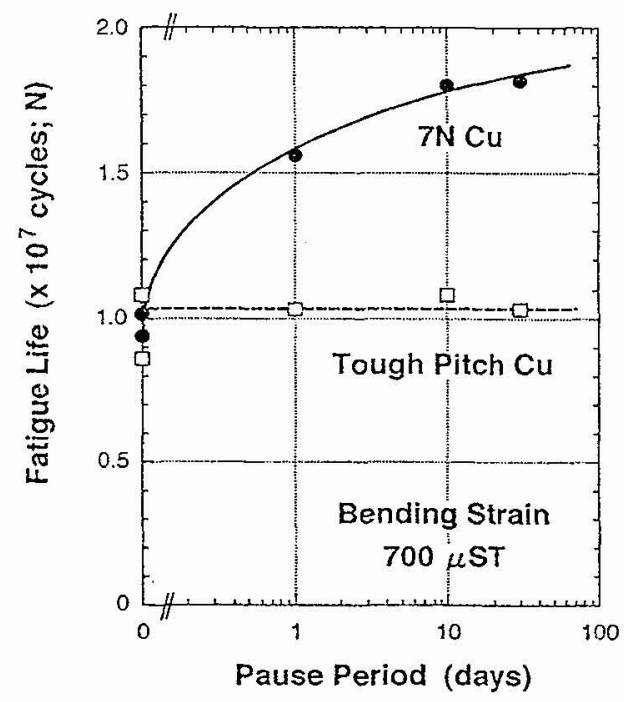

Fig.7 Relations between total fatigue failure cycles and a pause period.

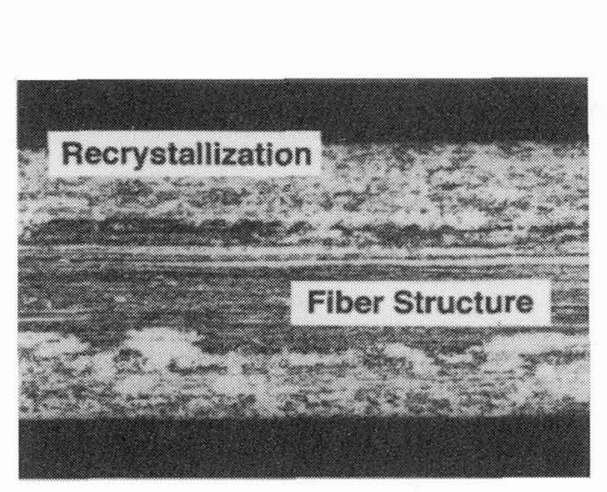

(a) $7 \mathrm{~N} \mathrm{Cu}$

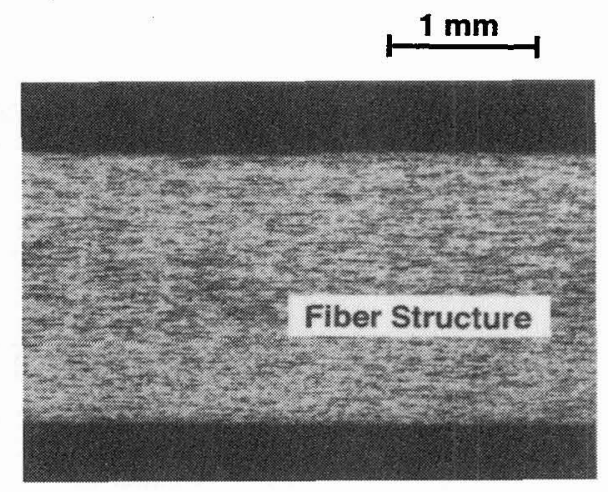

(b) Tough Pitch $\mathrm{Cu}$

Fig.8 Microstructures of longitudinal sections of (a)7N and (b)Tough Pitch copper wires aged for 10 days at R.T. as a pause period after $5 \times 10^{6}$ fatigue cycles. 


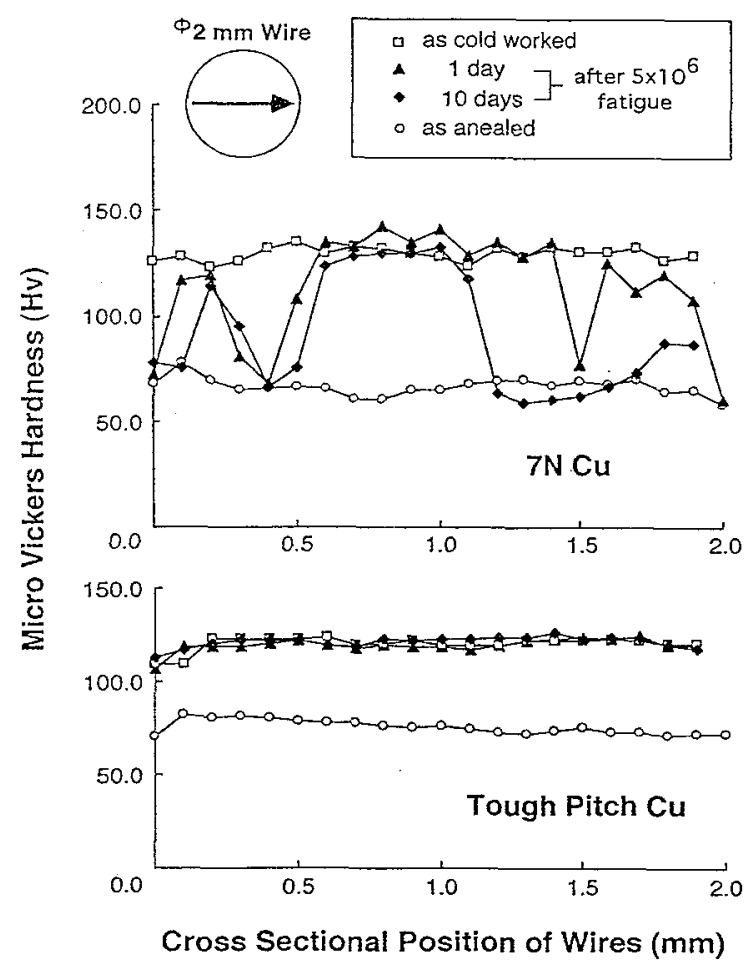

Fig.9 Hardness distributions of wire cross-section in $7 N$ and Tough Pitch copper wires.

\section{DISCUSSION}

Recrystallizations and consequent softening were observed in $7 \mathrm{~N}$ copper wire aged at room temperature after cold work. The extent depended on reduction or strains induced by cold work. Recrystallizations at the wire surface where the largest strain was induced during fatigue testing and a significant increase of fatigue life as a result were also observed in fatigue tests performed at room temperature. It is considered that strains accumulated during cold work or fatigue enhance recrystallization in $7 \mathrm{~N}$ copper. The rate of recrystallization is high enough compared with the service life of the material. This character gives a unique property to $7 \mathrm{~N}$ copper. It can recover from fatigue by itself during use and show excellent fatigue resistance.

\section{CONCLUSION}

From fatigue tests carried out by the rotational bending method at room temperature on $7 \mathrm{~N}, \mathrm{OFC}$ and Tough-Pitch copper wires, the following conclusions were obtained.

(1) The fatigue failure cycles of $7 \mathrm{~N}$ copper increased with an increasing pause period imposed during the fatigue test.

(2) Remarkable recrystallizations initiated from the wire surface occurred in $7 \mathrm{~N}$ copper after the pause period in the fatigue test.

(3) It is considered that strains accumulated during fatigue act as the driving force and $7 \mathrm{~N}$ copper recovers from fatigue by the effect of recrystallization. 


\section{References}

[1] M. Kato: "Application of Ultra-High-Purity Copper for Electric Wires and Conductors", Proc. of Ultra High Purity Base Metals (UHPM94), Kitakyusyu Fukuoka Japan, May 1994, (Jpn. Inst. Metals, Sendai, Japan, 1995), p441.

[2] A. Kurosaka, N. Tanabe, O. Kohno and O. Osanai: "High Purity Copper Wires", Proc. of Ultra High Purity Base Metals (UHPM94), Kitakyusyu Fukuoka Japan, May 1994, (Jpn. Inst. Metals, Sendai, Japan, 1995), p446.

[3] T. Nara and Y. Yamada: J. Jpn. Inst. Metals, 24(1960)744. [4] J. S. Smart, A. A. Smith and A. J. Phillips: AIME, 143(1941)272.

[5] B. F. Decker and D. Harker: Trans. AIME, 188(1950)887.

[6] V. A. Phillips and A. Phillips: J. Inst. Metals, 81(1952/53)185.

[7] R. Urao, M. Aoyama, M. Kaminaga, M. Oonuki and Y. Miyake: J. Jpn. Inst. Metals, 54(1990)1030. 